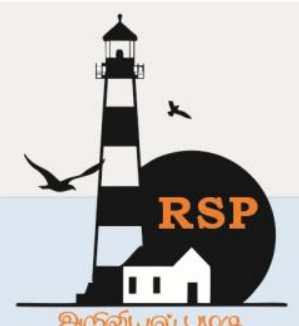

\title{
A Standard Reference Audio Tone Generator for Tuning Indian Classical Musical Instruments
}

\section{K P Deshmukh}

Associate Professor, Department of Electronics, Shri Shivaji Mahavidyalaya, Barshi-413411, Maharashtra, India

${ }^{1}$ kpdeshmukh@rediffmail.com

\begin{abstract}
This paper proposes a novel method for generating the standard reference musical notes for tuning the Indian Classical Musical String Instruments and may other musical instruments that need periodical retuning. Proper tuning of the musical instruments, before public performance, is must-to-do activity. Even a fine mistuning leads to improper musical notes. In this paper we have designed an embedded system, using standard microcontroller 8051, to obtain standard reference frequencies (notes) for three different octaves (saptak's). The output signal is conditioned to obtain near sinewave and reproduced into sound using audio amplifier. The control program is written in assembly language to select the reference note and an octave. The standard reference note frequencies are measured using $0.5 \mathrm{~Hz}$ accuracy digital frequency counter and displayed on $L C D$.
\end{abstract}

Keywords:standard, audio, tone, generator, tuning, indian, classical, musical, instruments

\section{Introduction}

Most of the Indian string instruments are tuned traditionally with a reference note from harmonium or similar instrument. But the main problem with this method is that the reference note is considered as a standard without any confirmation. Due to advent of digital technology it is now possible to produce standard reference notes or frequencies for the string type musical instruments. In this paper, the design of an embedded system using standard microcontroller 8051 is discussed. The advantage of this design is the accuracy of generating the standard reference notes to $100 \%$, at the same time displaying the reference frequency for the music performer. The Table.1 shows the standard reference frequency chart for Indian classical music. Slight variation in standard frequencies is

Table.1. Standard Reference Frequency Chart

\begin{tabular}{|c|c|c|c|c|c|c|c|c|c|c|c|c|c|}
\hline $\begin{array}{c}\text { Musical } \\
\text { Tonein } \\
\mathrm{Hz} \\
\end{array}$ & \multirow[t]{2}{*}{$\mathrm{Sa}$} & \multirow[t]{2}{*}{$\overline{R e}$} & \multirow[t]{2}{*}{$\operatorname{Re}$} & \multirow[t]{2}{*}{$\overline{G a}$} & \multirow[t]{2}{*}{$\mathrm{Ga}$} & \multirow[t]{2}{*}{$\mathrm{Ma}$} & \multirow[t]{2}{*}{$\overline{M a}$} & \multirow[t]{2}{*}{$\mathrm{Pa}$} & \multirow[t]{2}{*}{$\overline{D h a}$} & \multirow[t]{2}{*}{ Dha } & \multirow[t]{2}{*}{$\mathrm{Ni}$} & \multirow[t]{2}{*}{$\overline{N i}$} & \multirow[t]{2}{*}{$\mathrm{Sa}$} \\
\hline Octave & & & & & & & & & & & & & \\
\hline Upper & 520 & 558 & 590 & 626 & 664 & 702 & 744 & 787 & 837 & 884 & 941 & 995 & 1040 \\
\hline Middle & 260 & 280 & 296 & 314 & 332 & 351 & 372 & 394 & 419 & 443 & 470 & 500 & 520 \\
\hline Lower & 130 & 141 & 148 & 158 & 167 & 176 & 186 & 196 & 209 & 222 & 235 & 251 & 260 \\
\hline
\end{tabular}


www.rspsciencehub.com

observed between south and north Indian classical music. Few additional standard frequency notes are present in south Indian music style. But this chart confirms to the standard notes followed by north Indian classical music. The same philosophy could be extended for south Indian classical music.[1-3]
Volume 02 Issue 10 October 2020

the twelve different standard reference notes. Port2 3-bits (P2.3 to P2.5) are used for selecting one of the three octaves (Saptak). P2.2 pin is used to output a square wave of frequency of a standard reference note selected by performer.

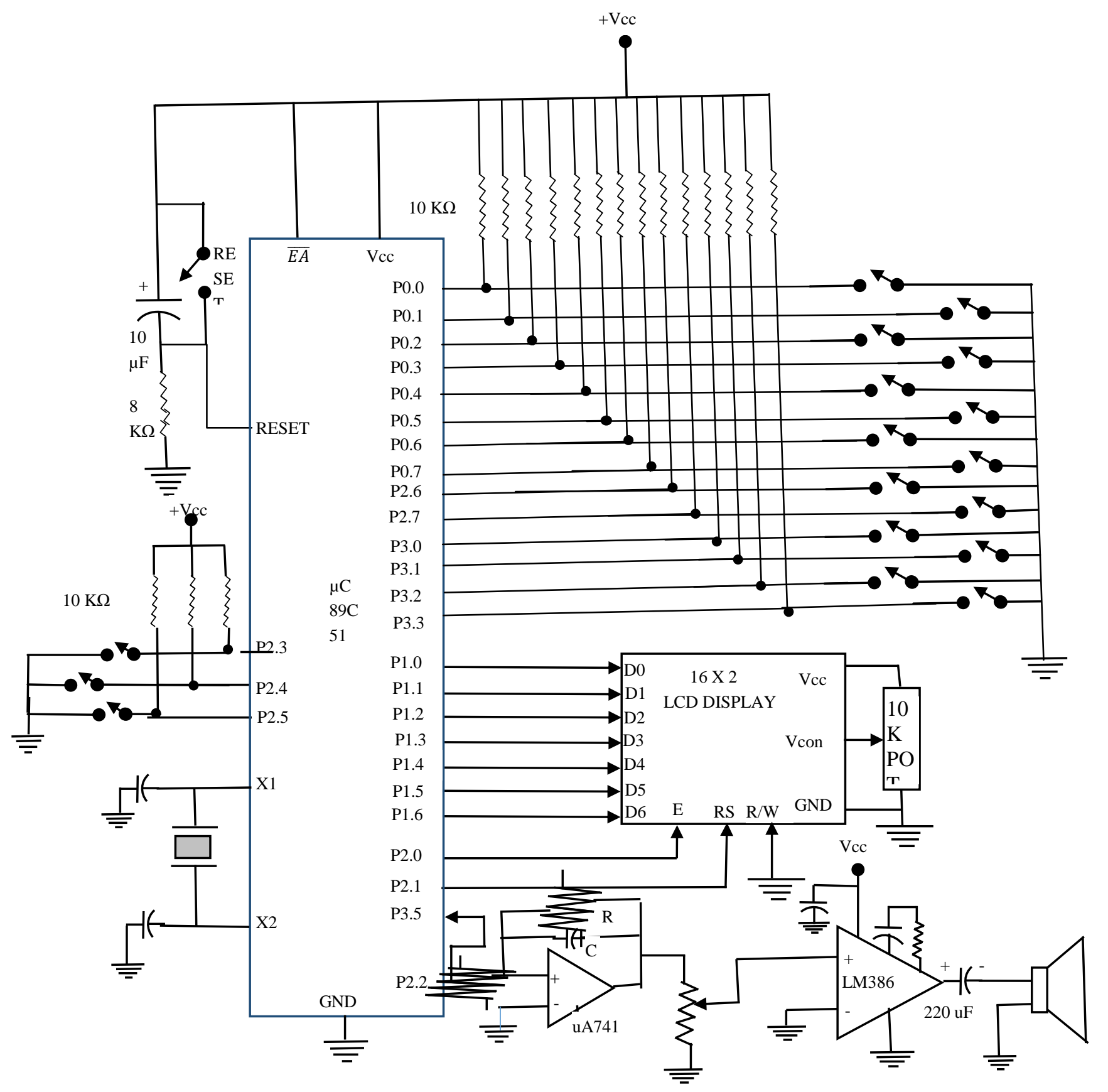

Fig.1. Embedded System Circuit Diagram

\section{2. haraware}

Fig.1. below shows basic circuit diagram of the embedded system designed. Port-0 8-bits (P0.0 to P0.7) and Port-2 2-bits (P2.6 and P2.7) and Port-3 2-bits (P3.0 and P3.1) are used for selecting one of
Port-1 7-bits (P1.0 to P1.6) are used for sending ASCII data toLCD and P2.0 and P2.1 bits are used for enabling ASCII data to LCD and selecting the command/data registers. The RC network along with manual RESET switch provides Power-OnReset and hardware reset to the microcontroller. A 


\section{www.rspsciencehub.com}

$12 \mathrm{MHz}$ crystal decides the internal clock frequency for the controller. The frequency feedback is achieved by connecting the squarewave output to the counter-1 input (P3.5). The square-wave output from pin P2.2 is converted into triangular wave form using OPAMP RC integrator. The integrator time period is kept much large compared to the highest frequency of the standard reference note to achieve a constant-slope triangular wave. The amplitude of the triangular wave is adjustable to provide a volume control function for the audio power amplifier using LM386, as shown in the fig.1.

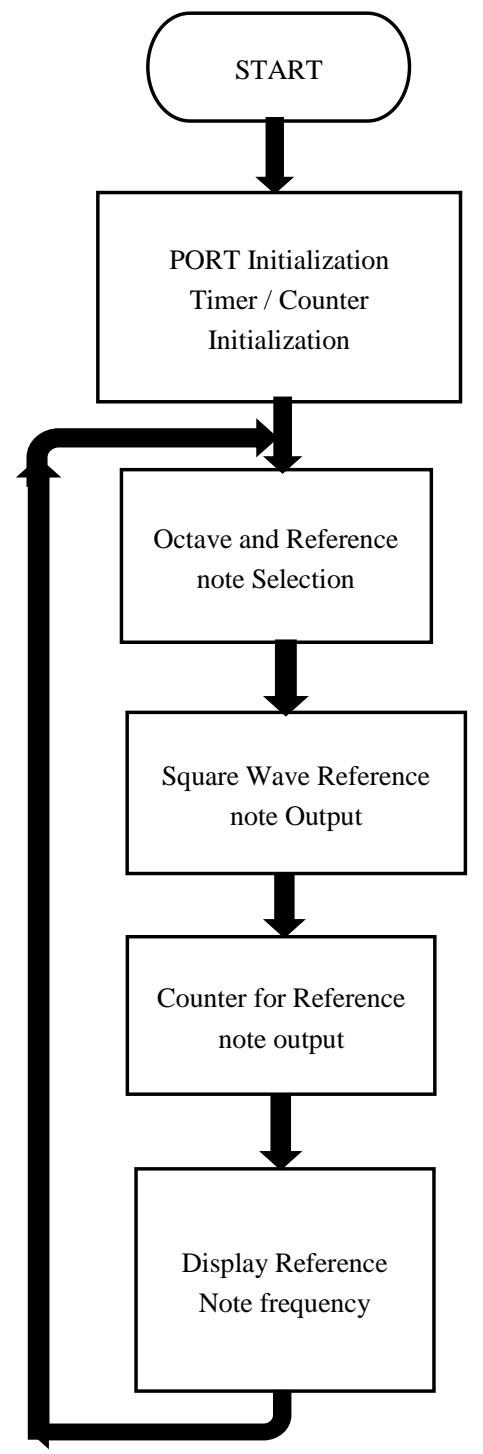

Fig.2. Embedded Svstem flowchart

\section{Software}

The programming flowchart for the designed embedded system is as shown in fig.2.The driving software for the designed hardware is written in assembly language for $\mu \mathrm{C} 8051$. Initially, the port
Volume 02 Issue 10 October 2020

and port pin initialization of the required pins is performed. Timer- 0 is used in mode- 1 (16-bit timer) for generating the square wave of appropriate reference note and octave selected.Timer-1 is used as a 16-bit counter to count the real-time frequency of the outputted note. The octave selection and reference note selection is obtained from the switch network. The updated frequency value is supplied to LCD display. The music performer has the choice to select one of the three octaves and one of the twelve notes from the selected octave. The Timer- 0 is initialized with appropriate hex value from the look-up table based on the octave and reference note selected.

\section{Conclusions}

It is possible to generate a standard reference note for those Indian classical musical instruments which need fine tuning occasionally or periodically. The testing of the designed system was performed in the Department of Music, Shri Shivaji Mahavidyalaya, Barshi-413411.

\section{Results}

An accuracy of $99.99 \%$ was obtained for the designed embedded system for thirty-six reference notes in-total.

\section{Acknowledgement}

The authors like to thank Department of Music and Department of Electronics for providing Laboratory facilities, electronic material for designing the system, and library access.

\section{References \\ Journals}

[1].GajjarK. and PatelM. (2017). Computational Musicology for Raga Analysis in Indian Classical Music: A Critical Review, Int. Journal of Comp. Appl., vol. 172 no. 9, pp $42-47$.

[2]. ShridharR. and GeethaT. V. (2006). Swara Identification for South Indian Classical Music, Proc. $9^{\text {th }}$ Int. Conf. on Inf. Tech., pp 143-144.

\section{Conferences}

[3]. KrishnaswamyA. (2004). Towards Modeling, Computer Analysis and Synthesis of Indian Ragams, Proc. FRSM2004, Chidambaram, India. 